\title{
A test of a functional group approach to detecting shifts in macroalgal communities along a disturbance gradient
}

\author{
J. C. Phillips ${ }^{1, *}$, G. A. Kendrick ${ }^{2}$, P. S. Lavery ${ }^{1}$ \\ ${ }^{1}$ Centre for Ecosystem Management, Edith Cowan University, Joondalup, Western Australia, 6027, Australia \\ ${ }^{2}$ Department of Botany, The University of Western Australia, Nedlands, Western Australia, 6907, Australia
}

\begin{abstract}
It has recently been proposed that the functional form group hypothesis developed in the 1980 s can be used as a tool to predict changes to algal community composition resulting from disturbance. This study tested whether the functional group model could detect changes in macroalgal community structure within one bioregion, by applying the model to a habitat (high relief limestone reef) exposed to different levels of physical disturbance (wave exposure). Macroalgal community structure was examined on 3 high relief limestone reef lines exposed to high, intermediate and low levels of wave-driven physical disturbance, which were used as a gradient of physical disturbance. Community structure was measured by determining the biomass and diversity at both the species and functional group levels. Comparisons between the 2 approaches were made using ANOVA (analysis of variance) of biomass data and derived diversity indices. Multivariate analysis techniques of ordination. Principal Axis Correlation (PCC) and ANOSIM (analysis of similarities) were used to detect patterns of assemblage change. The macroalgal assemblages were found to be highly variable, particularly within exposure levels, when examined at both the species and functional group levels. While both approaches revealed similar trends in the response of the algal community to physical disturbance, the functional group approach was less able to detect differences between levels of exposure. Use of the functional group approach resulted in considerable loss of information. Its use is not recommended for communities displaying high spatial heterogeneity without further rigorous testung of the model. Furthermore, algal functional groups need to be more clearly defined to overcome problems of assigning species to groups that do not easily fit the model.
\end{abstract}

KEY WORDS: Functional groups - Macroalgae - Disturbance - Limestone reef - Community structure Ecklonia radiata. Western Australia

\section{INTRODUCTION}

Studies of marine benthic algal communities have traditionally focused at the level of the individual species. Identifying assemblages to species level, however, is time-consuming and requires considerable taxonomic expertise. Furthermore, considerable species diversity and taxonomic uncertainty often prevent identification to species level. Alternatives to the spe-

- Present address: Department of Botany, University of Otago, PO Box 56, Dunedin, New Zealand

E-mail:c/op.lavery@cowan.edu.au cies-level approach include reducing taxonomic resolution (i.e. identifying to a higher taxonomic level such as Family) or dividing the biota into functional groups.

Littler \& Littler (1980) proposed the functional group model for macroalgae whereby morphologically and functionally similar macroalgae were grouped together for the purposes of studying community structure. Many authors have suggested a clear link between macroalgal form and function, and argue that predictable patterns of growth forms emerge under given levels of environmental stress or disturbance (Steneck \& Watling 1982, Littler \& Littler 1984, Dethier 1994, Steneck \& Dethier 1994). Hay (1994) suggested that functional groups could be used to illustrate the large 
ecological forces that change the distribution, abundance and diversity of macroalgal communities. A species-level approach could then be adopted to identify the species-specific differences that determine interactions within functional groups (Hay 1994).

Some studies have attempted to show that algal functional groups can be related specifically to levels of disturbance (Littler \& Littler 1984, Steneck \& Dethier 1994). Littler \& Littler (1984) found general support for the hypothesis that morphological, physiological and ecological adaptations can be related to the level of disturbance encountered. They concluded that it would be possible to predict community composition based on knowledge of disturbance levels in given environments, or vice versa. Steneck \& Dethier (1994) continued research in this direction by attempting to show that algal community composition can be predicted based on productivity potential and disturbance potential. They examined macroalgae in the western North Atlantic, the eastern North Pacific and the Caribbean and concluded that algal communities are more temporally stable and predictable when examined at the functional group level, compared to the species level. We question the validity of this conclusion, however, as their study drew comparisons across habitats and biogeographic zones. Steneck \& Dethier (1994) further argued that disturbance and productivity potentials are processes that structure algal communities in a form-specific manner, and that manmade alterations of either or both of these will result in predictable changes to community structure. If this is in fact the case, then the reciprocal should also hold. That is, community changes resulting from disturbance should be detectable using a functional group approach

We tested the ability of the functional group model to detect shifts in community structure. Changes in algal communities associated with Ecklonia radiata kelp forests were examined between limestone reefs subjected to different levels of wave-driven physical disturbance. By testing the hypothesis in one habitat type in a localised region, across a gradient of exposure to physical disturbance, conclusions may be drawn about the strength of the functional group approach in detecting change in macroalgal community structure, when compared with a species-level approach.

\section{METHODS}

Study area. Marmion Lagoon $\left(31^{\circ} 48^{\prime} \mathrm{S}, 115^{\circ} 42^{\prime} \mathrm{E}\right)$ is a shallow ( $<15 \mathrm{~m}$ deep) semi-enclosed body of water situated $20 \mathrm{~km}$ north of Perth, Western Australia (Fig. 1). Oceanic swells from the west and south-west dominate the local wave climate year round (Searle \&
Semeniuk 1985). Locally generated wind waves, in addition to swell, have a significant influence close inshore and during storm events (Searle \& Semeniuk 1985). Both types of waves are dampened, diffracted and refracted as they approach the coast by a series of 3 parallel limestone reefs. This dissipation of energy as waves encounter each successive reef line produces a gradient of physical disturbance ranging from highly exposed sites (offshore reefs) to sites of low exposure (inshore reefs). Wave heights at each reef line, measured simultaneously for $2 \mathrm{~h}$ on 9 July 1996 using a Yeo-Kal SDL (Model 606), were used to calculate the total energy per unit area of wave. These measurements were intended to provide an indication of relative energy levels at the 3 reef lines, and not to describe temporal and spatial variation in absolute energy levels. Energy at the offshore, midshore and inshore reef lines was 3899.05, 2054.21 and 970.23 $\mathrm{J} \mathrm{m}^{-2}$ respectively. We believe these differences in energy levels to be ecologically significant, as we will elaborate on in the 'Discussion'.

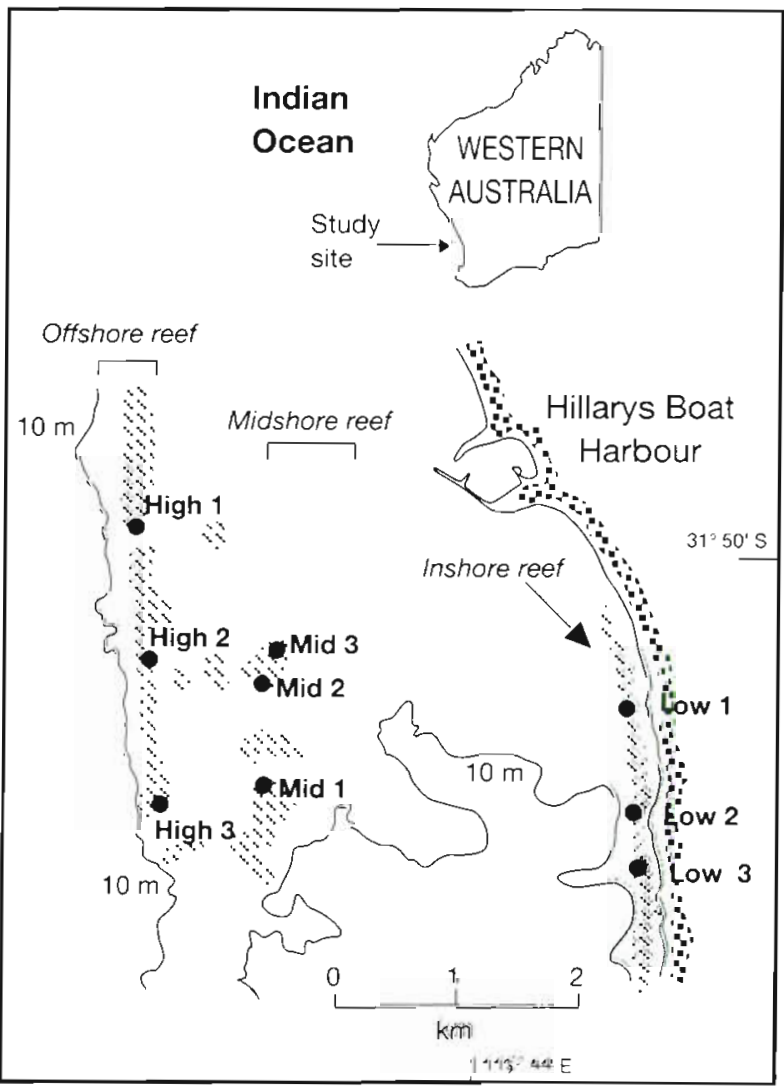

Fig. 1. Location of Marmion Lagoon, Western Australia. Three parallel reef lines (offshore, midshore and inshore), chosen to represent 3 levels of wave-driven physical disturbance, and 3 sampling sites on each reef (High 1 to 3 , Mid 1 to 3 , Low 1 to 3) are shown. The solid lines represent depth contours 
There was approximately $4.35 \mathrm{~km}^{2}$ of high relief reef (Johannes \& Hearn 1985) in the study area. High relief reef is defined as limestone reef showing considerable change in surface elevation (usually 1 to $3 \mathrm{~m}$ ) and occurred on all 3 sets of parallel reef. The kelp Ecklonia radiata (C. Agardh) J. Agardh is the dominant macrophyte on high relief reefs in Marmion Lagoon (Kirkman 1981).

Experimental design. The biomass of macroalgal communities was sampled on reefs exposed to 3 levels of physical disturbance. A 2-way nested sampling design was employed, whereby sampling of each disturbance level was replicated at 3 sites, giving a total of 9 sampling sites. The 2 factors considered were disturbance regime and sites within disturbance regimes. At each site, 10 replicate macroalgal samples were collected by SCUBA divers using randomly positioned $0.25 \mathrm{~m}^{2}$ quadrats and for purposes of analyses, data from these quadrats were averaged. Sampling involved a once-off effort within a $3 \mathrm{wk}$ period in the Australian autumn (April to May 1996). This design was based on the assumption that the 3 sites did not differ significantly in relation to other environmental variables (see following section).

Establishing sampling sites. Three sites were subjectively chosen on each line of reef to give a total of 9 sites. All sites conformed to a set of key environmental variables, namely: height above surrounding substrate $(>0.5 \mathrm{~m})$; depth of overlying water column $(\sim 6 \mathrm{~m})$, and; nature of reef substrate (limestone with consistent rugosity between sampling locations). Sites within each level of exposure were located 300 to $400 \mathrm{~m}$ apart.

Pilot study to determine optinum sample size. Due to the spatial patchiness observed in Perth's limestone reef communities a pilot study was conducted to determine the optimum size and number of replicate samples. A statistical analysis was performed on data collected in November 1995 from randomly placed $0.25,0.50$ and $0.75 \mathrm{~m}^{2}$ quadrats on limestone reefs within the low disturbance regime sites in Marmion Lagoon. Data were analysed for optimal quadrat size and sample size using the procedure outlined by Bros \& Cowell (1987). The minimum detectable difference (MDD) ( $\alpha=0.05,80 \%$ power) and precision were calculated for sample sizes of 6 to 20 replicates. From this, a sample size of 10 replicates of $0.25 \mathrm{~m}^{2}$ was selected (mean $\mathrm{MDD}=48.25 \%$ ). This was considered acceptable as no significant gain in resolving power would have been achieved by an increase in replicates, while a significant increase in sampling effort would have been required to reduce the MDD.

Collection and processing of macroalgae samples. For each replicate, all non-crustose macroalgae were removed by hand. Samples were stored on ice, returned to the laboratory and preserved using 4 to $5 \%$ buffered seawater formalin solution. Species were identified and functional group numbers assigned using the procedure outlined in the following section. Samples were then dried and weighed for dry weight before combusting for $2 \mathrm{~h}$ at $550^{\circ} \mathrm{C}$ to determine ashfree dry weight. Due to the logistical problems of ashing large volumes of the kelp Ecklonia radiata, only 5 plants were ashed and the mean loss on ignition $(23.96 \%)$ was deducted from the dry weights of remaining plants to give ash-free dry weights.

Biomass of crustose algae was calculated using a correlation between percentage cover and ash-free dry weight. Using a gridded $0.25 \mathrm{~m}^{2}$ quadrat $(5 \mathrm{~cm} \times$ $5 \mathrm{~cm}$ squares giving a total of 81 intercept points), all crustose algae from a known area were collected. Five samples were collected which was less than originally intended, but logistical constraints prevented the collection of a larger sample size. Samples were processed to ash-free dry weight and a regression analysis was performed on the data. The regression $\left(y=0.0769 x, R^{2}=0.8674, n=5, p=0.017\right)$ was then applied to the percentage cover of crustose algae recorded for each replicate (\% cover was estimated using the point-intercept method) to give an estimate of the biomass.

Assigning functional groups to species. Each species identified was assigned to the appropriate algal functional group based on the functional group model described in Steneck \& Dethier (1994). The following functional groups were examined: filamentous algae (Functional Group 2); foliose algae (FG 3); corticated foliose algae (FG 3.5); corticated terete algae (FG 4); leathery macrophytes (FG 5); articulated calcareous algae (FG 6); and crustose algae (FG 7). Some species, however, did not clearly fall into any particular group. In such cases, a judgment was made as to which functional group most closely approximated the functional form of the species in question, taking into consideration morphological and physiological characteristics. The life history stage of some other species collected meant that they were assigned to a functional group that differed from that of typical mature stage plants. Table 1 lists these species, the functional group assigned, and a brief justification for assigning them to the particular functional groups.

Data analysis. Data were analysed to determine whether differences in community structure resulting from exposure to different levels of physical disturbance were evident using a species level approach and, alternatively, using a functional group level approach. The 2 approaches were then compared to determine if they differed in sensitivity to detecting shifts in community composition. Biomass and diversity were used as measures of community structure, since these were the 2 community descriptors on 
Table 1. List of species that were difficult to assign functional groups (FG) to and justification for final decision made. FG 3 : foliose algae $_{i}$ FG 3.5: corticated foliose algae; FG 4: corticated terete algae; FG 5: leathery macrophytes; FG 6: articulated calcareous algae; FG 7: crustose algae

\begin{tabular}{|c|c|c|}
\hline Species & $\mathrm{FG}$ & Justification \\
\hline Dictyota sp. & 3 & Similar to FG 3.5 (corticated foliose algae) yet only a few cells thick and lacking cortication \\
\hline Lobophora variegata & 3 & As for Dictyota sp \\
\hline Zonaria turneriana & 3 & As for Dictyota sp. \\
\hline Tylotus obtusatus & 3.5 & $\begin{array}{l}\text { Mature plants are thickened and leathery, characteristic of the leathery macrophytes } \\
\text { (FG 5), yet specimen collected was young plant with relatively little thickening; struc- } \\
\text { turally more similar to corticated folıose algae (FG 3.5) }\end{array}$ \\
\hline Caulerpa distichophylla & 3.5 & $\begin{array}{l}\text { As for all Caulerpa spp., this alga is coenocytic and therefore unlike any FG. Assigned to } \\
\text { FG } 3.5 \text { (corticated foliose algae) as it most closely resembles its overall morphology and } \\
\text { ecological function }\end{array}$ \\
\hline Caulerpa brownii & 4 & AIso coenocytic; overall morphology resembling large corticated terete algae (FG 4) \\
\hline Caulerpa cactoides & 4 & As for C. brownii \\
\hline Codium cf harveyi & 4 & As for C brownii \\
\hline Laurencia elata & 4 & Slightly compressed thallus but physiology same as for other Laurencia spp. in FG 4 \\
\hline Champia viridis & 4 & $\begin{array}{l}\text { Thallus of regular hollow sections and lacking differentiation into outer cortex and inner } \\
\text { medulla characteristic of corticated foliose algae (FG 4); assigned FG } 4 \text { based on overall } \\
\text { morphology }\end{array}$ \\
\hline Gloiosaccion brownil & 4 & As for $C$ viridis \\
\hline Webervanbossea splachnoides & 4 & As for C. viridis \\
\hline Callophycus oppositifolius & 5 & Partıcular specimen collected had a thick, dense medulla giving it a tough leathery texture \\
\hline Metamastophora flabellata & 6 & $\begin{array}{l}\text { A calcified alga which although lacking genicula is otherwise analogous to articulated } \\
\text { calcareous algae (FG } 6)\end{array}$ \\
\hline
\end{tabular}

which Steneck \& Dethier (1994) drew their conclusions. Analyses were directed at detecting withinexposure and among-exposure differences. Amongexposure differences were explored using several multivariate techniques based on (dis)similarity coefficients derived from biomass data matrices, at both species and functional group levels.

Comparison of biomass at species and functional group levels: To test for differences among sites, mean biomass of each site was compared using a 2 -factorial nested ANOVA (analysis of variance) model in the software package SuperANOVA ${ }^{T M}$ (Abacus Concepts, Inc.). The biomass was divided into 3 categories: total biomass (all species combined); biomass of understorey species only; and biomass of the canopy species, Ecklonia radiata. Since the kelp E. radiata had high biomass compared to all other species (in most cases several orders of magnitude greater), it was felt that by splitting the biomass into understorey only and canopy only, differences between sites within an exposure might be revealed that were otherwise concealed by the dominance of the kelp biomass. Furthermore, as the habitat under investigation was essentially a kelp forest, the response of E. radiata to exposure to different levels of physical disturbance was of interest. At the functional group level, differences within an exposure were examined by comparing the biomass of each functional group separately for each site.

Prior to ANOVAs being conducted, Cochran's test (Winer et al. 1991) was used to test for homogeneity of variance. Where heterogeneity in variances was still present, data were rank transformed following the procedure outlined in Fowler \& Cohen (1990) for assigning ranks.

Comparison using diversity indices: Two measures of diversity were used at both the species and functional group levels. The first measure was Margalef's diversity index, $D$, derived using species richness $S$ and $N$ (total biomass summed over all $S$ species) (Magurran 1988), and is therefore responsive to slight changes in species richness. It was calculated as

$$
D=(S-1) / \ln N
$$

The second, the Berger-Parker index, is a dominance measure weighted towards the abundance of the most common species (Magurran 1988). The reciprocal of the Berger-Parker index, $N_{\infty}$, was adopted so that an increase in the value of the index accompanied an increase in diversity and a reduction in dominance (Magurran 1988) and was calculated as

$$
N_{\infty}=1 /\left(N_{\max } / N\right)
$$

where $N_{\text {max }}$ is the biomass of the most abundant species/functional group and $N$ is the total biomass.

Variances of all diversity index data sets were tested for homogeneity of variance using Cochran's test (Winer et al. 1991). As some data sets displayed heterogeneous variances, all were rank transformed prior to performing nested ANOVAs.

Patterns of assemblage change: Multivariate statistical analyses were used to explore patterns in macroalgal assemblages due to exposure to different levels 
of physical disturbance. The sum of the replicate species biomass and functional group biomass for each site were used. All data sets were $\log (n+1)$ transformed prior to analyses to account for the large number of zero counts.

Ordination: The multivariate statistical analysis package PATN (Belbin 1993) was used to conduct ordination of sites. To calculate the dissimilarity among sites, data were first associated using the Bray-Curtis association measure. Ordinations performed on the association matrix were 2-dimensional non-metric multidimensional scaling (MDS) ordinations.

Principal Axis Correlation $(P C C)$ : To investigate which species or functional groups were responding to the disturbance gradient, PCCs were performed against all ordinations (Belbin 1993), PCC is a multiple-linear regression program that determines the direction of best fit and the correlation coefficient of that fit for each species or functional group in the ordination space (Belbin 1993). The correlation coefficient was used as a rough indicator of the significance of each species or functional group (Belbin 1993). Those species or functional groups with a correlation coefficient greater than 0.8 were considered to be significantly influencing the ordination pattern.

Analysis of similarities: To test for differences between exposure levels and between sites within exposure levels, 2-way nested ANOSIM (analysis of similarities) was conducted using the PRIMER (Plymouth Routines In Multivariate Ecological Research) analysis package (Clarke 1993, Clarke \& Warwick 1994). ANOSIM is a non-parametric permutation procedure that is applied to the (rank) similarity matrix underlying the ordination of sites (Clarke \& Warwick 1994). ANOSIM tested the null hypothesis that there was no difference among sites within exposure levels and among exposure levels.

Data used were $\log (n+1)$ transformed total biomass and understorey biomass, at both the species and functional group level. Using Bray-Curtis association values, ANOSIM calculated a global $R$ statistic which is the average of ranked similarity values of pairs of replicates (Clarke 1993). The $R$ statistic was then recalculated for all possible permutations of the replicates, and the distribution of permuted $R$ values compared to the original $R$ value to give a significance value (Clarke \& Warwick 1994). The significance value, shown as a percentage, indicates the number of times a better assemblage pattern was obtained from random rearrangement of the association matrix, compared to the original pattern shown in the data (Clarke \& Warwick 1994). In providing an indication of the significance of the observed pattern, ANOSIM overcomes the subjective analysis of ordination plots.
Table 2. Number of taxa and percentage of total taxa recorded for each functional group (FG)

\begin{tabular}{|c|c|c|c|}
\hline \multicolumn{2}{|c|}{ Functional group } & $\begin{array}{c}\text { No. of } \\
\text { axa recorded }\end{array}$ & \multirow{2}{*}{$\begin{array}{c}\% \text { of } \\
\text { total taxa } \\
3.7\end{array}$} \\
\hline FG 2 & Filamentous algae & 3 & \\
\hline FG 3 & Foliose algae & 7 & 8.5 \\
\hline FG 3.5 & Corticated foliose algae & 33 & 40.2 \\
\hline FG 4 & Corticated terete algae & 18 & 22.0 \\
\hline FG 5 & Leathery macrophytes & 14 & 17.1 \\
\hline FG 6 & Articulated calcareous algae & 6 & 7.3 \\
\hline \multirow[t]{2}{*}{ FG 7} & Crustose algae & 1 & 1.2 \\
\hline & Total & 82 & 100.0 \\
\hline
\end{tabular}

\section{RESULTS}

\section{Macroalgal sampling}

A total of 82 taxa were recorded (Table 2). This species richness is comparable to the number of species recorded in studies of nearby limestone reefs; 59 by Walker et al. (1991), 120 by Montgomery \& Walker (1996) and 202 by Simpson \& Ottaway (1987). The 82 taxa were unevenly distributed across the 7 algal functional groups, with over $40 \%$ of all taxa belonging to FG 3.5 (corticated foliose algae). FG 4 was also species-rich ( $22 \%$ of all taxa). The least species-rich group (excluding FG 7 which was only identified to family) was FG 2 (filamentous algae) (Table 2).

\section{Functional group level biomass comparisons}

None of the 7 functional groups showed significant differences in mean biomass along the exposure gradient (Table 3). Only 2 functional groups (FG 6 and FG 7) were significantly different in mean biomass among sites within exposure levels (Table 3, Fig. 2a, b). The remaining functional groups, while not statistically significant, showed greater differences within exposure levels than among exposure levels, as shown for Functional Group 4, corticated terete algae (Table 3, Fig. 2c). The overall trend, therefore, was variability in mean biomass within reef lines but no evidence of differences along the exposure gradient.

\section{Diversity index comparisons}

For Margalef's index, the trend in differences among sites was the same for both species and functional group approaches (Fig, 3a). Diversity was almost always proportionally higher at the species level, however, due to the loss of information when species are 
Table 3. Results of 2-tactorial nested analysis of variance (ANOVA) tests for differences in functional group (FG) biomass between the 9 sampling sites within exposure levels. Rank transformed data were used in all cases

\begin{tabular}{|c|c|c|c|c|}
\hline Variable & df & MS & $F$ & $p$-value \\
\hline \multicolumn{5}{|c|}{ Among exposure levels } \\
\hline FG 2 & 2 & 827.465 & 1.084 & $0.4422 \mathrm{~ns}$ \\
\hline $\mathrm{FG} 3$ & 2 & 153.025 & 0.302 & $0.7593 \mathrm{~ns}$ \\
\hline FG 3.5 & 2 & 3135.519 & 2.972 & $0.1943 \mathrm{~ns}$ \\
\hline FG 4 & 2 & 1285.719 & 1.959 & $0.2856 \mathrm{~ns}$ \\
\hline FG 5 & 2 & 2498.662 & 3.104 & $0.1860 \mathrm{~ns}$ \\
\hline FG 6 & 2 & 311.490 & 0.186 & $0.8394 \mathrm{~ns}$ \\
\hline FG 7 & 2 & 678.425 & 0.409 & $0.6967 \mathrm{~ns}$ \\
\hline \multicolumn{5}{|c|}{ Among sites within exposure levels } \\
\hline FG 2 & 6 & 763.171 & 2.151 & $0.1000 \mathrm{~ns}$ \\
\hline FG 3 & 6 & 506.312 & 1.392 & $0.2509 \mathrm{~ns}$ \\
\hline FG 3.5 & 6 & 1055.000 & 1.752 & $0.1627 \mathrm{~ns}$ \\
\hline $\mathrm{FG} 4$ & 6 & 656.350 & 1.236 & $0.3017 \mathrm{~ns}$ \\
\hline FG 5 & 6 & 805.008 & 1.697 & $0.1738 \mathrm{~ns}$ \\
\hline FG 6 & 6 & 1676.950 & 8.229 & $0.0001 \cdots$ \\
\hline FG 7 & 6 & 1660.512 & 2.949 & $0.0374^{\circ}$ \\
\hline
\end{tabular}

pooled inio functionai groups. Diversity was higher in Low exposure and High exposure sites (Fig. 3a). The midshore reef sites (Mid 1 to 3 ) had the lowest diversity and the least variation among sites.

Differences between species and functional group level diversity were not as pronounced using the Berger-Parker index due to the dominance of kelp at both levels (Fig. 3b). Variation among sites was greatest at the low level of exposure, which also showed the highest diversity (Fig. 3b). This indicated that kelp was proportionately less important at low exposure sites and biomass was more evenly distributed between species and functional groups

ANOVA of the differences in both diversity indices revealed no significant differences among exposure levels at either the species or functional group levels (Table 4). Sites within exposure levels were more variable, and Margalef's index was significantly different at both the species and functional group levels (Table 4)

\section{Patterns of assemblage change}

\section{Ordination}

Ordinations performed on total biomass and understorey biomass (i.e. minus the kelp Ecklonia radiata) indicated that shifts in assemblages were more strongly displayed at the species level (Fig. 4).

For total biomass at the functional group level, sites from the low exposure level (Low 1 to 3 ) formed a tight

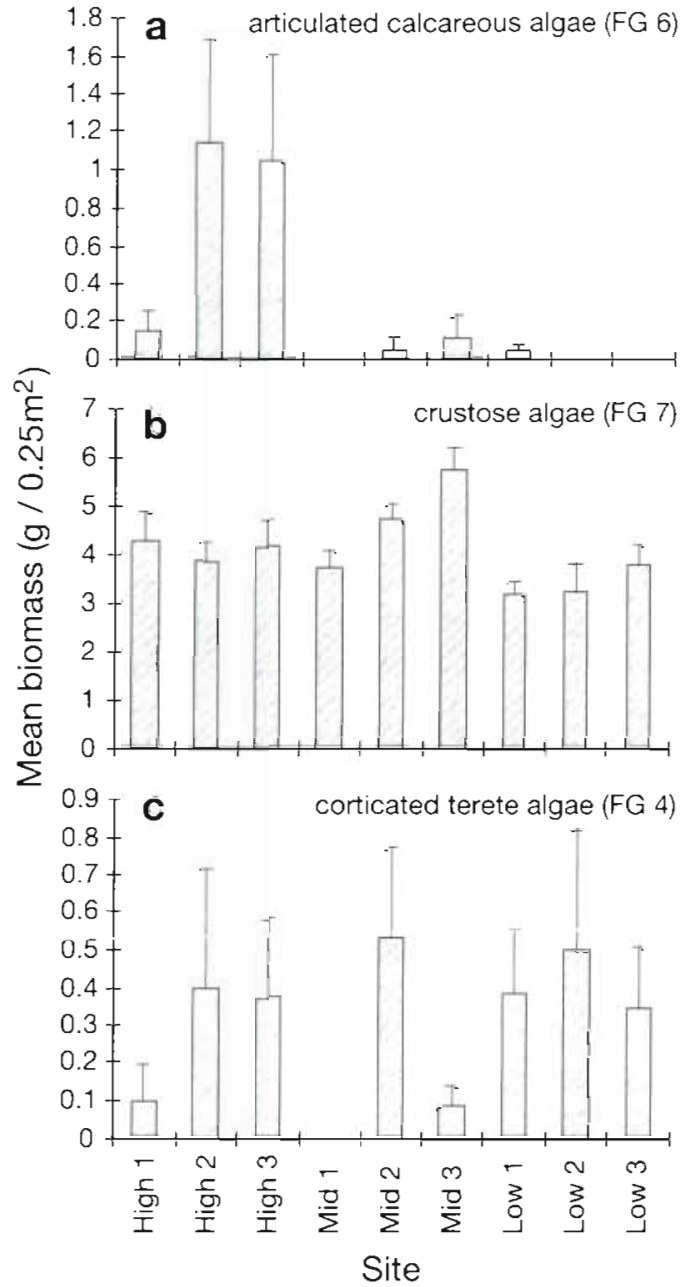

Fig. 2. Mean biomass ( $+\mathrm{SE}, \mathrm{n}=10$ ) of macroalgae recorded at 3 sampling sites $(1,2,3)$ within each level of exposure (High, Mid, Low). (a) Articulated calcareous algae (FG 6);

(b) crustose algae (FG 7); (c) corticated terete algae (FG 4)

cluster (Fig. 4a). High 2 and 3 sites grouped close together but the remaining High site was not separate from the Mid sites (Fig. 4a). When total biomass data at the species level was used to ordinate sites, the gradient from sites at a low level of exposure through to sites at a high level was more evident (Fig. 4b), although the Low 1 to 3 sites were not as tightly clustered as in Fig. 4a. There was also a rotation of the ordination pattern so the differences between Low and High sites occurred on the second MDS axis.

The ordination of sites based on understorey biomass at the functional group level (Fig. 4c) showed a similar pattern to that shown for total biomass (Fig, 4a), although Low sites were not as tightly clustered. The removal of kelp biomass did, however, rotate the position of sites along the axes. Similarly, the species level ordination (Fig. 4d) showed close to a mirror image of 

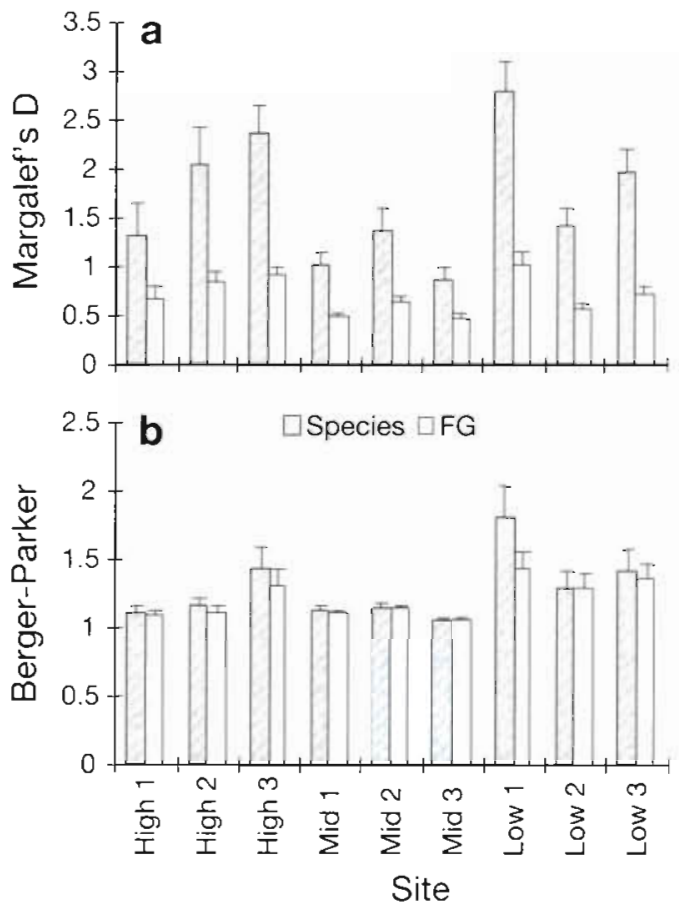

Fig. 3. Mean diversity indices ( $\mathrm{SE}, \mathrm{n}=10$ ) at the species level and functional group ( $F G$ ) level for 3 sampling sites $(1,2,3)$ within each level of exposure (High, Mid, Low). (a) Margalef's $D$ index; (b) Berger-Parker index

Fig. $4 \mathrm{~b}$, with sites having been switched from left to right after the removal of kelp biomass. This indicated that kelp was having a similar influence on assemblage composition across sites.

Table 4. Results of 2-factorial nested ANOVA tests for differences in diversity using 2 indices (Margalef's, Berger-Parker) at species and functional group ( $F G$ ) levels. Rank transformed data were used in all cases

\begin{tabular}{|c|c|c|c|c|}
\hline Variable & $\mathrm{df}$ & MS & $F$ & $p$-value \\
\hline \multicolumn{5}{|c|}{ Among exposure levels } \\
\hline \multicolumn{5}{|l|}{ Species level } \\
\hline Margalef's & 2 & 4.823 & 1.644 & $0.3296 \mathrm{~ns}$ \\
\hline Berger-Parker & 2 & 3265.033 & 2.482 & $0.2312 \mathrm{~ns}$ \\
\hline \multicolumn{5}{|l|}{ FG level } \\
\hline Margalef's & 2 & 0.363 & 1.518 & 0.3503 ns \\
\hline Berger-Parker & 2 & 3679.033 & 3.450 & $0.1668 \mathrm{~ns}$ \\
\hline \multicolumn{5}{|c|}{ Among sites within exposure levels } \\
\hline Margalef's & 6 & 2.934 & 4.339 & $0.0068^{\cdots}$ \\
\hline Berger-Parker & 6 & 1315.483 & 2.470 & $0.0675 \mathrm{~ns}$ \\
\hline \multicolumn{5}{|l|}{ FG level } \\
\hline Margalef's & 6 & 0.239 & 3.169 & $0.0285^{\circ}$ \\
\hline Berger-Parker & 6 & 1066.333 & 2.087 & $0.1081 \mathrm{~ns}$ \\
\hline
\end{tabular}
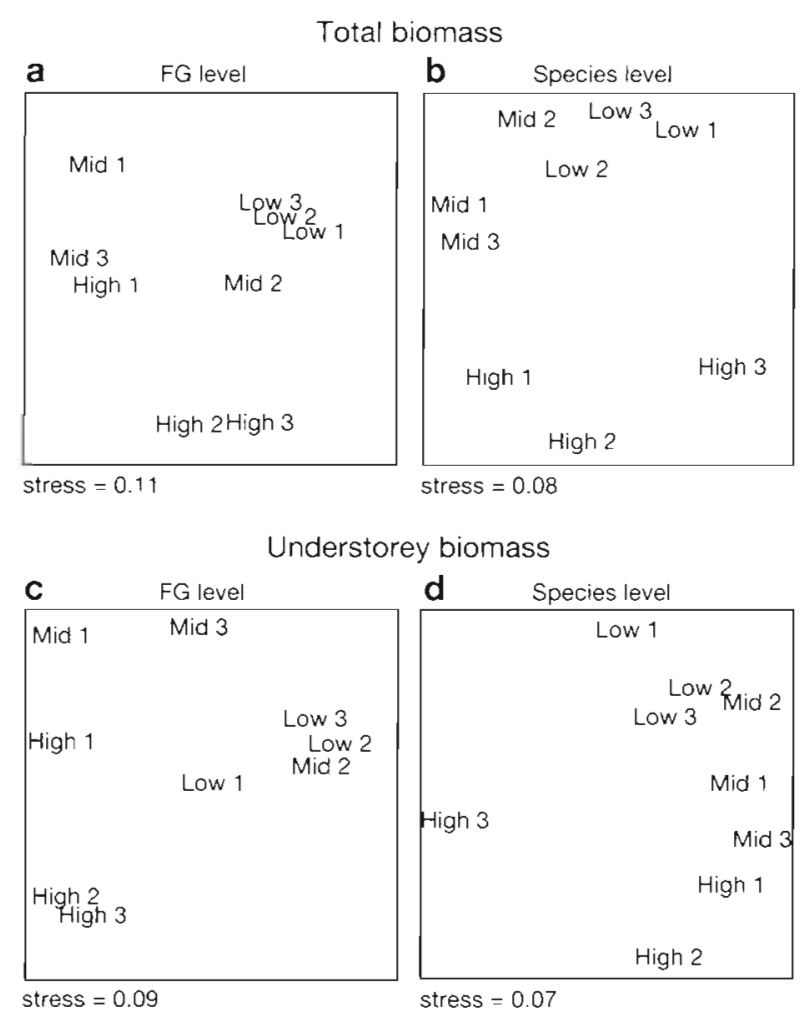

Fig. 4. Two-dimensional non-metric multidimensional scaling (MDS) ordinations of the 9 sampling sites, using $\log (n+1)$ transformed biomass data in all cases. (a) Total biomass at the functional group (FG) level. (b) Total biomass at the species level. (c) Understorey biomass at the FG level. (d) Understorey biomass at the species level

The stress values of both species level ordinations were lower than the corresponding functional group analyses. Species level ordinations, therefore, provided better representation of the assemblage patterns.

\section{Principal Axis Correlation (PCC)}

PCCs (Belbin 1993) were performed against each of the ordinations shown in Fig. 4. Four functional groups were shown to be significantly influencing the ordination pattern based on total biomass (Table 5). The strongest correlation was for FG 6 (articulated calcareous algae) which in Fig. 2a showed relatively high biomass at the high level of exposure yet was virtually absent at the low level sites. FG 3.5 and FG 4 also had high correlation coefficients (Table 5). The distribution of FG 4 across sites within exposures was more variable although considerably less variation was seen among sites at the low level of exposure (Fig. 2c). The lowest correlation coefficient shown in Table 5 was for FG 5, which consisted predominantly of kelp biomass. The important trend in the abundance of this func- 
Table 5. Functional groups with a correlation coefficient $>0.8$ following Principal Axis Correlation (PCC) against non-metric ordination of sampling sites based on total biomass at the functional group level, as shown in Fig. 4 a. + ve: overall trend

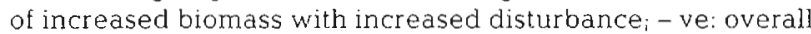
trend of decreased biomass with increased disturbance

\begin{tabular}{|lcc|}
\hline Functional group & $\begin{array}{c}\text { Response to } \\
\text { increased } \\
\text { disturbance }\end{array}$ & $\begin{array}{c}\text { Correlation } \\
\text { coefficient }\end{array}$ \\
\hline FG 3.5 (corticated foliose) & - ve & 0.9403 \\
FG 4 (corticated terete) & - ve & 0.9208 \\
FG 5 (leathery macrophytes) & + ve & 0.8464 \\
FG 6 (articulated calcareous) & +ve & 0.9787 \\
\hline
\end{tabular}

tional group was the considerably lower amount of biomass collected at all low exposure sites (Fig. 5). All 4 groups mentioned above showed the most pronounced biomass differences between the low level of exposure and the other 2 levels, which explains the tight clustering of all low sites in Fig. 4a.

At the species level, 17 species were significantly influencing the ordination pattern based on total species biomass in Fig. 4b (Table 6). The first 3 species shown in Fig. 6 (Amphiroa anceps, Haliptilon roseum and Sargassum cf. spinuligerum) occurred almost exclusively at high exposure sites (Fig. 6a-c). Dictymenia sonderi (Fig. 6d) was collected at all exposure levels, but not all sites, and was most abundant on all sites within the low level of exposure. Pterocladia lucida was collected at all 9 sites and, although variation among sites was high, there was a trend toward increasing biomass at the low level of exposure (Fig. 6e). It is worth noting that while the corticated foliose group (FG 3.5) generally responded negatively to increased disturbance (Table 5), there were some species within that functional group which responded positively (e.g. Callophycus dorsiferus, Plocamium preissianum; Table 6).

For the ordination of sites based on understorey biomass at the functional group level (Fig. 4c), PCC analysis showed that 3 functional groups significantly responded to the disturbance gradient (Table 7 ). The relative abundance of FG 4 and FG 6 across levels of exposure has been discussed earlier in this section, but it is interesting to note that removal of the kelp data results in increases in the correlation coefficients of these groups (Tables $5 \& 6$ ). The significance of FG 5 after the exclusion of kelp biomass was also high (Table 7 ) and it showed a pattern of relatively high abundances at all sites at the high level of exposure (Fig. 7).

For understorey biomass at the species level, most species listed in Table 8 as having a sig-

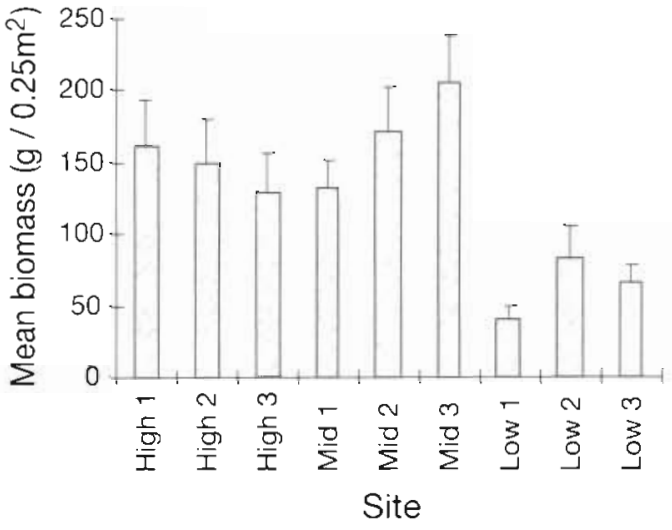

Fig. 5. Mean biomass (+ SE) of leathery macrophytes (FG 5) recorded at 3 sampling sites $(1,2,3)$ within each level of exposure (High, Mid, Low)

nificant influence on the ordination shown in Fig. 4 d were also important in driving the pattern shown for total biomass (Table 6). The relative abundance of some of these species across levels of exposure has been discussed earlier. Two other species that responded significantly to the exposure gradient are shown in Fig 8. Plocamium preissianum was collected only at high exposure sites (Fig. 8a), again in contrast to the general trend of FG 3.5 species, while Euptilota articulata was most abundant at the low exposure level and absent at high exposure sites (Fig. 8b)

Table 6. Species with a correlation coefficient $>0.8$ following PCC against non-metric ordination of sampling sites based on total biomass at the species level, as shown in Fig. 4b. FG: functional group. +ve: overall trend of increased biomass with increased disturbance, - ve: overall trend of decreased biomass with increased disturbance

\begin{tabular}{|c|c|c|c|}
\hline Species & $\mathrm{FG}$ & $\begin{array}{l}\text { Response to } \\
\text { increased } \\
\text { disturbance }\end{array}$ & $\begin{array}{l}\text { Correlation } \\
\text { coefficient }\end{array}$ \\
\hline Amphiroa anceps & 6 & $+v e$ & 0.9421 \\
\hline Callophycus dorsiferus & 3.5 & + ve & 0.8234 \\
\hline Chauviniella coriifolia & 3.5 & + ve & 0.9630 \\
\hline Dictymenia sonderi & 3.5 & - ve & 0.8988 \\
\hline Erythrymenia minuta & 3.5 & + ve & 0.8692 \\
\hline Euptilota articulata & 4 & - ve & 0.8020 \\
\hline Haliptilon roseum & 6 & $+v e$ & 0.8964 \\
\hline Jeannerettia pedicellata & 3.5 & - ve & 0.8583 \\
\hline Lobophora variegata & 3 & + ve & 0.8061 \\
\hline Metagoniolithon radiatum & 6 & + ve & 0.8276 \\
\hline Plocamium preissianum & 3.5 & + ve & 0.8584 \\
\hline Pterocladia lucida & 3.5 & - ve & 0.8782 \\
\hline Rhodopeltis borealis & 6 & $+v e$ & 0.8578 \\
\hline Rhodymenia sonderi & 3.5 & - ve & 0.8113 \\
\hline Sargassum cf. spmuligerum & 5 & + ve & 0.9459 \\
\hline Sargassum recruits & 3.5 & $+v e$ & 0.8353 \\
\hline Sargassum subg. Phyllotrichia & 5 & + ve & 0.8290 \\
\hline
\end{tabular}




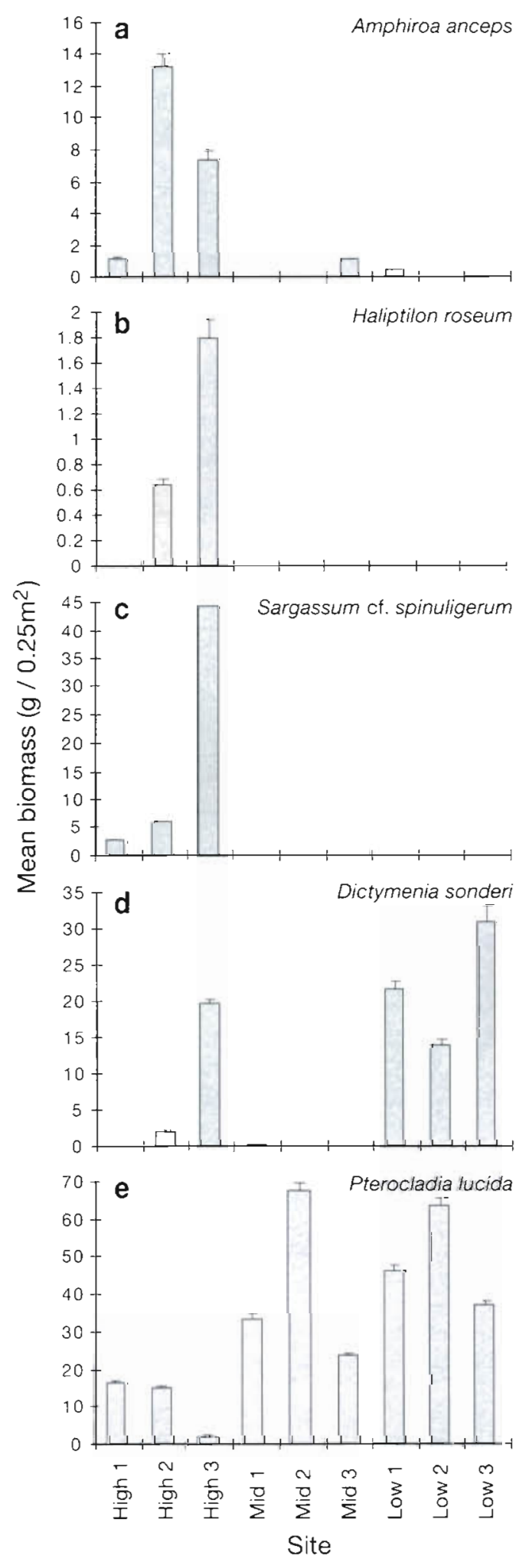

Fig. 6. Mean biomass ( $+\mathrm{SE}, \mathrm{n}=10$ ) of macroalgae recorded at 3 sampling sites $(1,2,3)$ within each level of exposure (High, Mid, Low). (a) Amphiroa anceps; (b) Haliptilon roseum; (c) Sargassum cf. spinuligerum; (d) Dictymenia sonderi (e) Pterocladia lucida
Table 7. Functional groups with a correlation coefficient $>0.8$ following PCC against non-metric ordination of 9 sampling sites based on understorey biomass at the functional group level, as shown in Fig. 4c. + ve: overall trend of increased biomass with increased disturbance; - ve: overall trend of decreased biomass with increased disturbance

\begin{tabular}{|lcc|}
\hline Functional group & $\begin{array}{c}\text { Response to } \\
\text { increased } \\
\text { disturbance }\end{array}$ & $\begin{array}{c}\text { Correlation } \\
\text { coefficient }\end{array}$ \\
\hline FG 4 (corticated terete) & $\begin{array}{l}\text {-ve } \\
\text { FG 5 (leathery macrophytes) }\end{array}$ & 0.9909 \\
FG 6 (articulated calcareous) & +ve & 0.9900 \\
& & 0.8960 \\
\hline
\end{tabular}

Analysis of similarities (ANOSIM)

Two-way nested ANOSIM conducted on total biomass and understorey biomass at the species level demonstrated significant differences among exposure levels and among sites within exposure levels (Table 9). This indicated that the chance of achieving a stronger pattern than that shown in the original species level data sets was small.

At the functional group level, there were significant differences among exposure levels and sites within exposure based on total biomass data (Table 9). For understorey biomass, significant differences were only apparent among sites within exposures (Table 9).

Overall, ANOSIM revealed that stronger patterns were evident in the assemblages when they were analysed at the species level, both among exposures and among sites within exposures.

\section{DISCUSSION}

Overall, the species level approach was more able to detect changes to community structure along the

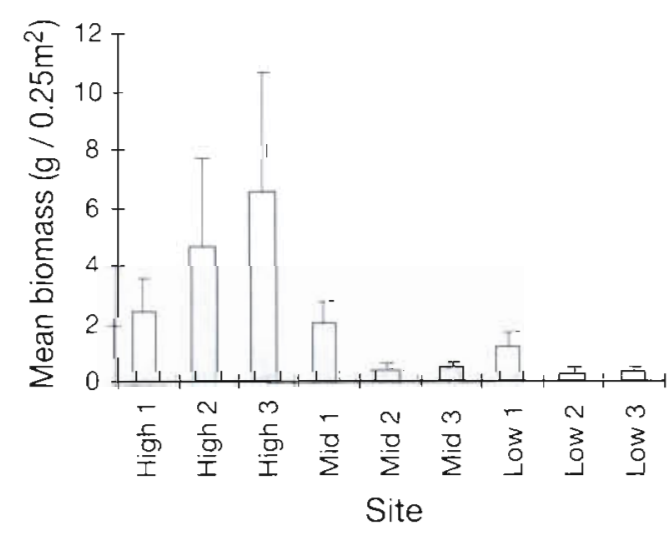

Fig. 7. Mean biomass ( $\mathrm{SE}, \mathrm{n}=10$ ) of FG 5 (leathery macrophytes) for understorey data only, recorded at 3 sampling sites $(1,2,3)$ within each level of exposure (High, Mid, Low) 
Table 8. Species with a correlation coefficient $>0.8$ following PCC against non-metric ordination of 9 sampling sites based on understorey species biomass at the species level, as shown in Fig. 4d. FG: functional group. + ve: overall trend of increased biomass with increased disturbance; - ve: overall trend of decreased biomass with increased disturbance

\begin{tabular}{|c|c|c|c|}
\hline Species & $\mathrm{FG}$ & $\begin{array}{l}\text { Response to } \\
\text { increased } \\
\text { disturbance }\end{array}$ & $\begin{array}{c}\text { Correlation } \\
\text { coefficient }\end{array}$ \\
\hline Amphirod anceps & 6 & + ve & 0.8516 \\
\hline Chauviniella coriifolia & 3.5 & + ve & 0.8559 \\
\hline Euptilota artıculata & 4. & $-v e$ & 0.8438 \\
\hline Jania sp. & 6 & + ve & 0.8395 \\
\hline Plocamium preissianum & 3.5 & $+v e$ & 0.9393 \\
\hline Pterocladia lucida & 3.5 & - ve & 0.8080 \\
\hline Rhodymenia sp. & 3.5 & + ve & 0.8174 \\
\hline Sargassum cf. spinuligerum & 5 & $+v e$ & 0.9225 \\
\hline Sargassum recruits & 3.5 & +ve & 0.8586 \\
\hline
\end{tabular}

disturbance gradient when compared with the functional group level approach. This is attributable to the amount of variability of species responses incorporated into each functional group. Although several individual species and functional groups responded systematically to the disturbance gradient, there was no

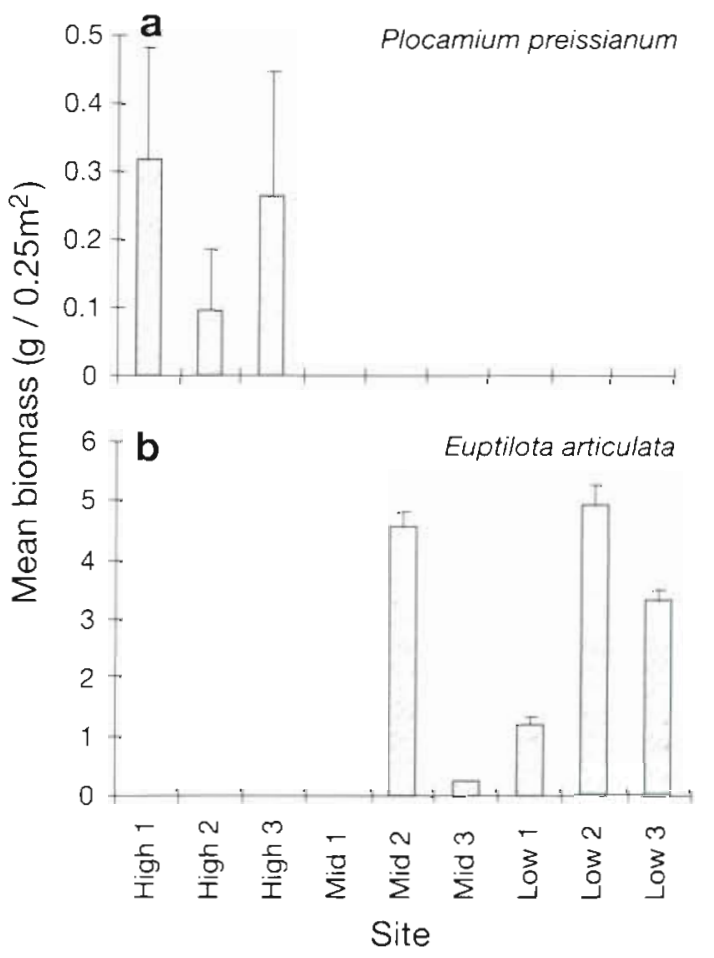

Fig. 8. Mean biomass ( $\mathrm{SE}, \mathrm{n}=10$ ) of macroalgae recorded at 3 sampling sites $(1,2,3)$ within each level of exposure (High, Mid, Low). (a) Plocamium preissianum; (b) Euptilota articulata consistent response of all species within many functional groups. The loss of information when pooling species into functional groups reduced measures of diversity and patterns of assemblage change were less evident between reef lines.

\section{Species level versus functional group level approaches}

Biomass of individual species and functional groups

It is worth opening the discussion on how individual species and functional groups responded to the exposure gradient by looking at the assemblages occurring at the mid level of exposure. When examined at the univariate level, algal assemblages on the midshore reef line did not show a systematic response to the exposure gradient. Total biomass and kelp biomass (and, consequently FG 5 biomass) were generally higher on the midshore reef line, and were accompanied by lower understorey biomass. Crustose algae (FG 7) biomass was higher compared to reef lines with comparatively less kelp, supporting Kennelly's (1987a, b, 1989) conclusions that crustose algae cover is associated with the low light conditions below the kelp canopy.

Several hypotheses as to what conditions allow kelp to dominate on the midshore reef line can be forwarded. Firstly, environmental conditions on the midshore reef line may be generally more favourable for settlement of kelp propagules. Alternatively, episodic storm events that create gaps in the kelp canopy allowing other species to invade may not impact as severely

Table 9. Results of 2-way nested ANOSIM testing for differences among exposure levels and sites within exposures, using $\log (n+1)$ transformed biomass data. Data were associated using the Bray-Curtis association measure. The maximum number of permutations possible among exposure levels and among sites within exposures were 10 and 280 respectively. FG: functional group

\begin{tabular}{|c|c|c|}
\hline \multirow[t]{2}{*}{ Data set } & \multicolumn{2}{|c|}{ Significance value } \\
\hline & $\begin{array}{l}\text { Among } \\
\text { exposure } \\
\text { levels }\end{array}$ & $\begin{array}{c}\text { Among } \\
\text { sites within } \\
\text { exposures }\end{array}$ \\
\hline Total species biomass & $0.4 \% \cdots$ & $0.1 \% \cdots$ \\
\hline Total FG biomass & $1.8 \%$ & $2.0 \%$ \\
\hline Understorey species biomass & $0.4 \% \cdots$ & $0.0 \% \cdots$ \\
\hline Understorey FG biomass & $10.4 \% \mathrm{~ns}$ & $2.2 \%$ \\
\hline \multicolumn{3}{|l|}{ ns: not statistically significant } \\
\hline
\end{tabular}


as they do on the offshore and inshore reefs, due to some degree of buffering afforded by the relatively close proximity to the offshore reef line. It may also be a complex interaction of these 2 factors, or others, that is responsible for the observed trends.

Despite the seemingly inconsistent trends of kelp and understorey components, many individual species responded in a systematic way to the exposure gradient. Articulated calcareous species such as Amphiroa anceps and Haliptilon roseum were more prevalent at high levels of disturbance, presumably because they are theoretically adapted to withstand such conditions. Conversely, many foliose species, such as Dictymenia sonderi and Pterocladia lucida, which morphologically appear less able to withstand the higher levels of disturbance, flourished under the less stressful conditions on the inshore reef.

Similarly, in some cases, individual functional groups showed predictable and systematic responses to the exposure gradient. The articulated calcareous (FG 6) and leathery macrophyte (FG 5) groups, which due to their structural complexity have a relatively high degree of resistance to physical damage, were more abundant at higher levels of disturbance while lower abundance on the inshore reef line may have been due to competition for primary space by faster-growing, less complex forms. However, the observed abundances of these 2 functional groups is in direct contrast to the generalised model presented by Steneck \& Dethier (1994).

The systematic response displayed by these groups prompts the notion that it may be possible to monitor physical disturbance using indicator functional groups, as opposed to indicator species. The results from this study, however, suggest that responses are not predictable for all functional groups due to the amount of variability in physiological responses encompassed in one functional group. As an example, the thin, sheet-like foliose forms (FG 3) which includes the sea lettuce Ulva sp. would not be expected to withstand high levels of physical disturbance given its delicate structure. In this study, however, this group was in fact most abundant on the offshore reef line. Similarly, Plocamium preissianum and Dictymenia sonderi are examples of 2 species that belong to the same functional group yet responded in an opposite manner to the disturbance gradient; $P$. preissianum responded positively to higher levels of disturbance while $D$. sonderi responded negatively. It may be argued that this simply reflects a reduced kelp canopy on the inshore reef, and $D$. sonderi is physiologically capable of responding to an associated increase in light levels. However, the important point to be made is that the amount of variation in physiological response is so great within some functional groups that it reduces the predictability of the group as a whole. Dethier (1994) investigated the amount of variation within one functional group, crustose algae, and concluded that crusts varied widely in their responses to both disturbance and productivity potential. Indicator functional groups, if they are to be used, should therefore be selected with caution, based on a sound knowledge of the predicted response of the group as a whole given the range of physiological responses within the group. This requires that the function of all the species in each group is known and not simply assumed (Underwood \& Petraitis 1993).

Following from the above, Steneck \& Dethier's (1994) general model predicts that with increasing disturbance there should be a loss of leathery macrophyte biomass, followed by decreases in the biomass of articulated calcareous and corticated algae. It was not our intention to test this northern hemisphere-derived general model, however the results presented in the previous paragraph clearly show that these generalised responses of functional groups cannot be assumed.

\section{Diversity measures}

Underlying trends at the species level of diversity were reflected at the functional group level. Differences between levels of exposure were, however, much more pronounced as species diversity. At the level of functional groups, differences in diversity between reef lines were greatly reduced with the result that reef lines appeared to have similar levels of assemblage diversity. Although it must be remembered that using the functional group model adopted for this study there can only be a maximum functional group richness of 7 groups, this only serves to highlight the effect of summarising information on community structure into a fairly small number of functional groups. Furthermore, the similarity of dominance at the species and functional group levels showed how diversity can be significantly influenced by one species within a functional group.

The use of diversity measures can also be misleading at the functional group level because significant changes in community structure may occur without any reduction in functional group diversity. For example, the loss of certain species from an area as a result of disturbance would not be accompanied by a reduction in functional group richness as long as at least one other species of the same functional form persisted. Monitoring of community change at the species level would obviously be more sensitive to detecting such changes. 
Monitoring for community change in term of shifts in dominance may be appropriate at the functional group level in certain circumstances. If one particular functional form is expected to respond more significantly to a disturbance gradient than other forms, this shift would be detected using a diversity measure that accounts for the degree of dominance by one group. If dominance of an algal assemblage is of interest, a functional group approach could be more appropriate than a species level approach in some situations. A particular disturbance may, for example, result in the proliferation of numerous opportunistic 'nuisance' species of the same functional form, all equally dominant. Examined at the species level, the assemblage would appear relatively diverse due to the lack of domination by one species. Of more interest to managers, however, would be the fact that the assemblage had become dominated by an opportunistic growth form, which would be more evident at the functional group level.

\section{Patterns of assemblage change}

The existence of a physical disturbance gradient effected a turnover of species and functional groups between reef lines. This turnover was, however, more evident when assemblages were examined the species level. This pattern of assemblage change across the disturbance gradient was also reflected in the degree of similarity of assemblage composition between reefs lines. The greater sensitivity of the species level approach in detecting these assemblage shifts suggests that while individual species are responding to the disturbance gradient, at the functional group level there is simply replacement of species within a functional group.

Species richness and diversity of assemblages on the offshore and inshore reef lines were more similar to each other than they were to midshore assemblages. Again, examination of assemblage patterns at the species level revealed this more clearly, even when the effects of the dominance of kelp were removed from analyses. The adoption of a functional group approach to looking for shifts in the assemblage as a whole meant that a similar loss of information occurred to that noted when assessing assemblage diversity.

\section{Definition of functional groups}

Problems were encountered with the definition of functional groups. If functional groups are to be of use in the analysis of ecological components, they must represent clear functional units with predictive value
(Walter \& Ikonen 1989). Although Littler \& Littler (1984) pointed out that the algal functional group model was intended to represent points along a continuum rather than discrete groups, this study has shown that significant functional information may be lost in the adoption of the functional group model currently in use.

A large proportion of species identified (14 out of $82 ;$ refer to Table 1) did not clearly fit any of the algal functional groups outlined in the most recent model proposed by Steneck \& Dethier (1994). Two of the difficulties that arose when assigning functional groups to species were attributable to the life history stage collected (i.e. Tylotus obtusatus and Callophycus oppositifolius), a problem in definition that was anticipated by Littler \& Littler (1984), while one species (Metamastophora flabellata) does not strictly conform to the description of the group which it was assigned to. The remaining 11 species, however, have morphological, anatomical and physiological characteristics distinct from those currently incorporated into the functional group model.

Notable examples of such distinct forms were the coenocytic algae collected, which included Caulerpa spp. and Codium cf, harveyi. Coenocytes are unlike any of the functional forms described by Steneck \& Dethier (1994) and probably warrant a separate group, particularly since they are widespread (Round 1981, Lüning 1990, Phillips 1990).

Hollow, tubular algae also presented a problem when assigning functional groups. These species (Gloiosaccion brownit, Champia viridis and Webervanbossea splachnoides) have no internal differentiation into an outer cortex and inner medulla and hence lack structural complexity, but were placed in the functional group with such characteristics based on similar overall morphology. A more appropriate group for such species would be the saccate cushion-like form group originally proposed by Littler (1980) but omitted from later functional group models.

It is interesting to note that Littler himself appears to have had difficulties in assigning functional groups to species, further demonstrating the need for better definition of groups. A comparison of Littler's (1980) study with later work by Littler \& Arnold (1982), both conducted on the Pacific Coast of southwestern North America, revealed that 5 species (Pterocladia capillacea, Endocladia muricata, Gelidium pusillum, G. purpurascens and $G$. robustum) placed in the 'delicately branched' group in the former study were placed in the 'coarsely branched' group in the latter study. Similarly, Pelvetia fastigiata and the kelp Egregia menziesii were originally included in the 'coarsely branched' group but were later classified by Littler \& Arnold (1982) into the 'thick leathery' group. While some of these inconsistencies may in fact be due to the particular life history 
stage or part of the thallus under examination, no explanation was given for the new assignment of species to functional groups (Littler \& Arnold 1982).

If biogeographic comparisons are to be made on the basis of functional form models, a revision of the definition of functional groups is required so that the model is less generalised and there is less ambiguity when classifying certain species. Functional forms that presently don't fit the model should also be incorporated as new groups, or a consensus reached as to their classification within the current model. Alternatively, functional group models could be developed specific to the context in which they are to be applied (e.g. for southern hemisphere temperate waters) so that they account for regionally endemic or abundant forms.

\section{Management implications}

Any attempt to detect changes in community structure need to be conducted at the scale at which management decisions are made. In this study, conducted at a local scale (10s of $\mathrm{km}^{2}$ ), we have demonstrated that the species level approach is more sensitive to detecting community shifts. Thus within this bioregion, the species level approach is more capable of detecting changes. Despite species having highly variable distributions and abundances, a functional group approach proved to be the worse option for the temperate reef communities studied. The functional group approach did not perform as well as the species approach, which was attributable to the amount of variability encompassed in each functional group. This raises questions as to how robust the functional group model actually is.

In light of these observations, it must be pointed out, however, that both approaches failed to reveal a strong change in community structure along the gradient of wave disturbance. Explanation for this may be that the communities have, over time, become so well adapted to the environmental conditions that, as a whole, they have evolved survival strategies that enable them to withstand the level of physical disturbance at each reef line. Alternatively, it may be that, even though there was a 3 -fold increase in the amount of wave energy at the offshore reef, this range of disturbance may in ecological terms fall within the tolerance limits of the reef communities. That is, the ecological threshold of disturbance for this kelp forest community may not have been reached.

\section{Conclusions}

The fundamental problem encountered when attempting to monitor for changes in community struc- ture was that a species response is not always a functional group response. Assumptions cannot be made that all species will respond the same as the functional group as a whole, due to the variability of species responses in a single functional group. Small scale shifts in community structure were separated out by the species and not by the functional groups, as functional groups tended to summarise and generalise the community information beyond the point of detectable change. Use of individual functional groups showed more promise, but a better understanding of the physiological responses incorporated into each group is required. Only when this variability has been accounted for can a decision be made as to which functional group is most appropriate as an indicator, that is, which is most likely to respond in a measurable way to the particular disturbance in question.

The use of functional groups as a measure of diversity is not recommended, based on the results of this study. A significant loss of information, resulting from the summation of information on community structure at the functional group level, was noticed. There are some exceptions to this conclusion. The functional group approach may legitimately be used to detect shifts in the dominant algal form. This would again, however, require a good understanding of responses of individual species. In situations where resources are limited (either taxonomic expertise or time) the functional group approach will offer distinct cost- and timebenefits. These benefits may, however, be of fset by the reduced sensitivity of this approach.

The comparative lack of sensitivity of the functional group approach to detecting changes resulting from wave-driven physical disturbance in local kelp forest communities does not mean that such an approach would be inapplicable to other disturbance types. Chemical disturbance, for example, may affect different physiological functions of algae than physical disturbance does, and produce a more predictable and discernible trend at the functional group level. What can be concluded, however, is that Steneck \& Dethier's (1994) claim to the generality of the functional group model does not hold true for the type of disturbance and macroalgal communities examined in this study. Even if it were argued that this study was limited by the fact that sampling was only conducted in one season, and that trends in functional groups may be more discernible in one or more other seasons, this actually only substantiates the conclusion that the model is difficult to generalise. A better definition of the functional group model is required before we can continue to test the applicability of this approach for other disturbance types and other communities 
Acknowledgements. This study was part of an Honours project carried out by J.C.P. at Edith Cowan University, Western Australia. G.A.K. and Meredith Campey collected data necessary for the pilot study. Field assistance was provided by $\mathrm{H}$. Astıll, G. Clapin, J. Eyres, R. Griffiths, M. Heller, A. Kendrick, S. Kivell, S. Montgomery, C. Oldham, B. Riegler, M. Vanderklift and $\mathrm{K}$. Wheeler. Thanks are due to the CSIRO Division of Fisheries, Western Australia, for providing equipment required for wave height measurements. We are particularly grateful to Dr Ross Sanders for assisting with the analysis of wave data, Mat Vanderklift for statistical advice and Dr John Huisman for helping with algal identifications.

\section{LITERATURE CITED}

Belbin L (1993) PATN technical reference. CSIRO Division of Wildlife and Ecology, Canberra

Bros WE, Cowell BC (1987) A technique for optimizing sample size (replication). J Exp Mar Biol. Ecol 114:63-71

Clarke KR (1993) Non-parametric multivariate analyses of changes in community structure. Aust J Ecol 18:117-143

Clarke KR, Warwick RM (1994) Change in marine communities: an approach to statistical analysis and interpretation. Natural Environment Research Council, Plymouth, UK

Dethier MN (1994) The ecology of intertidal algal crusts: variation within a functional group. J Exp Mar Biol Ecol $177: 37-71$

Fowler J, Cohen L (1990) Practical statıstics for field biology. John Wiley \& Sons, Chichester

Hay ME (1994) Species as 'noise' in community ecology: do seaweeds block our view of the kelp forest? Trends Ecol Evol 9:414-416

Johannes RE, Hearn CJ (1985) The effect of submarine groundwater discharge on nutrient and salinity regimes in a coastal lagoon off Perth, Western Australia. Estuar Coast Shelf Sci 21:789-800

Kennelly SJ (1987a) Physical disturbances in an Australian kelp community. I. Temporal effects. Mar Ecol Prog Ser 40 : $145-153$

Kennelly SJ (1.987b) Physical disturbances in an Australian kelp community. II. Effects on understorey species due to differences in kelp cover. Mar Ecol Prog Ser 40: $155-165$

Kennelly SJ (1989) Effects of kelp canopies on understorey species due to shade and scour. Mar Ecol Prog Ser 50: $215-224$

Kirkman $\mathrm{H}$ (1981) The first year in the life history and the survival of the juvenile marine macrophyte, Ecklonia radiata (Turn) J. Agardh. J Exp Mar Biol Ecol 55:243-254

Littler MM (1980) Morphological form and photosynthetic performances of marine macroalgae: tests of a functional/ form hypothesis. Botanica Mar 22:161-165
Littler MM, Arnold KE (1982) Primary productivity of marine macroalgal functional form groups from southwestern North America. J Phycol 18:307-311

Littler MM, Littler DS (1.980) The evolution of thallus form and survival strategies in benthic marine macroalgae: field and laboratory tests of a functional form model. Am Nat 116: $25-44$

Littler MM, Littler DS (1984) Relationships between macroalgal functional form groups and substrata stability in a subtropical rocky-intertidal system. J Exp Mar Biol Ecol $74: 13-34$

Lüning K (1990) Seaweeds: their environment, biogeography and ecophysiology. Wiley-Interscience, New York

Magurran AE (1988) Ecological diversity and its measurement. Croom Helm, London

Montgomery SC, Walker DI (1996) Dawesville offshore flora survey. Department of Botany, University of Western Australia, Perth

Phillips JA (1990) Chlorophyta and Euglenophyta. In: Clayton MN, King RJ (eds) Biology of marine plants. Longman, Melbourne, p 183-212

Round FE (1981) The ecology of the algae. Cambridge University Press, Cambridge

Searle DJ, Semeniuk V (1985) The natural sectors of the inner Rottnest Shelf coast adjoining the Swan Coastal Plain. J R Soc West Aust 67:116-136

Simpson CJ, Ottaway JR (1987) Description and numerical classification of marine macroepibenthic conllununities in the proposed Marmion Marine Park near Perth, Western Australia. In: Moore E (ed) Collected technical reports on the Marmion Marine Park, Perth, Western Australia Western Australian Environmental Protection Authority Technical Series No. 19, Perth, p 93-123

Steneck RS, Dethier MN (1994) A functional group approach to the structure of algal-dominated communities. Oikos 69 $476-498$

Steneck RS, Watling L (1982) Feeding capabilities and limitation of herbivorous molluscs: a functional group approach. Mar Biol 68:299-319

Underwood AJ, Petraitis PS (1993) Structure of intertidal assemblages in different locations: how can local processes be compared? In: Ricklefs RE, Schluter D (eds) Species diversity in ecological communities: historical and geographical perspectives. The University of Chicago Press, Chicago, p 36-51

Walker DI, Kendrick GA, Brearley A (1991) Quinns Rocks marine flora and fauna survey report. Department of Botany, University of Western Australia, Perth

Walter DE, Ikonen EK (1989) Species, guilds, functional groups: taxonomy and behavior in nematophagous arthropods. J Nematol 21:315-327

Winer BJ, Brown DR, Michels KM (1991) Statistical principles in experimental design. McGraw-Hill, New York

Manuscript first received: January 24, 1997

Revised version accepted: April 25, 1997 